\title{
AVALIAÇÃO DA QUALIDADE MICROBIOLÓGICA DA RICOTA COMERCIALIZADA EM SUPERMERCADOS DO ESTADO DE SÃO PAULO
}

\author{
Natacha Deboni Cereser, ${ }^{1}$ Oswaldo Durival Rossi Júnior, ${ }^{2}$ Patricia Gelli Feres de Marchi, ${ }^{3}$ Viviane de \\ Souza, ${ }^{4}$ Marita Vedoveli Cardozo ${ }^{5}$ Thais Mioto Martineli ${ }^{6}$ \\ 1. Doutoranda da Universidade Estadual Paulista Júlio de Mesquita Filho, Faculdade de Ciências Agrárias e Veterinárias de Jaboticabal, Departamento \\ de Medicina Veterinária Preventiva e Reprodução Animal. E-mail: natachacereser@yahoo.com.br \\ 2. Professor adjunto da Universidade Estadual Paulista Júlio de Mesquita Filho, Faculdade de Ciências Agrárias e Veterinárias de Jaboticabal. \\ 3. Doutoranda da Universidade Estadual Paulista Júlio de Mesquita Filho, Faculdade de Ciências Agrárias e Veterinárias de Jaboticabal, \\ 4. Pesquisadora da Embrapa Caprinos e Ovinos. Sobral, CE. E-mail: vivianesouzavet@yahoo.com.br \\ 5. Mestranda da Universidade Estadual Paulista Júlio de Mesquita Filho, Faculdade de Ciências Agrárias e Veterinárias de Jaboticabal, \\ 6. Doutoranda da Universidade Estadual Paulista Júlio de Mesquita Filho, Faculdade de Ciências Agrárias e Veterinárias de Jaboticabal,
}

\section{RESUMO}

Dentre os queijos frescos, ou com elevada umidade, destaca-se a ricota. Trata-se de um produto muito consumido, tendo em vista seu reduzido teor de gordura e baixo custo, sendo indicado em dietas com restrições em lipídios, além de ser acessível à maioria das classes sociais. A ricota apresenta elevada atividade de água e diversidade nutricional, fatores que propiciam a proliferação da microbiota oportunista e patogênica, reduzindo a segurança desse alimento. Nesse contexto, o presente estudo objetivou avaliar a qualidade microbiológica da ricota produzida sob controle higiênico-sanitário permanente. De um total de sessenta amostras de duas marcas comerciais analisadas, $68,3 \%$ foram consideradas impróprias para o consumo humano, devido à presença de elevadas populações de coliformes termotolerantes. Quanto ao Staphylococcus coagulase positivo, $18,3 \%$ das amostras estavam em desacordo com os padrões estabelecidos pela Agência Nacional de Vigilância Sanitária (Anvisa). Altas contagens também foram observadas para microrganismos mesófilos e bolores e leveduras. A presença de microrganismos como $E$. coli $\mathrm{e} S$. aureus no produto avaliado pode desencadear surtos de doenças transmitidas por alimentos e deve ser motivo de preocupação por parte das autoridades de saúde pública.

PALAVRAS-CHAVES: Coliformes termotolerantes, Staphylococcus aureus, ricota e saúde pública.

\section{ABSTRACT}

\section{EVALUATION OF THE MICROBIOTICAL QUALITY OF RICOTTA CHEESE MARKETED IN SUPERMARKETS OF THE STATE OF SÃO PAULO}

Ricotta is distinguishable among different kinds of fresh cheese, or with high humidity. It is a highly consumed product for the reduced fat content and low cost, being indicated in diets with lipid restrictions, besides being economically accessible to most of the social classes. Ricotta cheese presents high water activity and nutritional diversity, factors that propitiate the proliferation of opportunist and patogenic microbiota, reducing the safety of these victuals. In that context, the present study aimed at evaluating the microbiotical quality of ricotta cheese produced under permanent hygienic-sanitarium control. Of a total of 60 samples from the two commercial brands analyzed, $68.3 \%$ were considered inappropriate for human consumption due to the presence of high populations of thermotolerant coliforms. With regard to Staphylococcus coagulase positive, $18.3 \%$ of the samples were in disagreement with the patterns established by the Agência Nacional de Vigilância Sanitária (Anvisa). High scores were also observed for mesophils microorganisms, mould and yeasts. The presence of microorganisms as E. coli and S. aureus in the evaluated product can unchain the outbreak of diseases transmitted by food and it should be a reason of concern by public health authorities.

KEYWORDS: Thermotolerant coliforms, Staphylococcus aureus, ricotta cheese and public health. 


\section{INTRODUÇÃO}

As exigências do mercado em relação a alimentos mais nutritivos e saudáveis têm aumentado o consumo de produtos lácteos com baixo teor de gordura. Dentre os mais populares, destaca-se a ricota, um queijo de soro de significativa importância econômica e alimentar, consumido mundialmente e também em larga escala no Brasil (SOUZA et al., 2002; RIBEIRO et al., 2005).

Contudo, a ricota é um produto cuja conservação é limitada devido aos teores elevados de umidade de $(70 \%$ a $73 \%$ ) e disponibilidade de nutrientes, como sais minerais e lactose (MAIA et al., 2004). Essas condições, aliadas ao $\mathrm{pH}$ geralmente alto, favorecem a multiplicação de microrganismos contaminantes, sejam estes deteriorantes ou patogênicos, que apresentam ações deletérias sobre os queijos, alterando suas características sensoriais e representando risco à saúde pública (PINTADO et al., 2001).

Dentre os inúmeros microrganismos que podem contaminar esse tipo de queijo, destaca-se a Listeria monocytogenes, que tem sido associada a doença emergente de origem alimentar. Os laticínios são particularmente suscetctíveis à contaminação por Listeria monocytogenes, pelo fato de a bactéria ser frequentemente isolada nas granjas leiteiras, nas ordenhadeiras mecânicas e no ambiente industrial, multiplicando-se sob temperatura de refrigeração $\left(2\right.$ a $\left.10^{\circ} \mathrm{C}\right)$ (GUERRA \& BERNARDO, 1999).

O gênero Salmonella possui ampla distribuição no ambiente e tem sido isolada em alimentos de origem animal e derivados, constituindo um problema para a agroindústria e a saúde pública. Estudos epidemiológicos realizados em vários países situam as salmonelas entre os agentes patogênicos mais frequentemente associados a Doenças de Transmissão Alimentar (DTA). Segundo FEITOSA et al. (2003), a presença de Salmonella em queijo de coalho e queijo de manteiga tem sido relatada em algumas pesquisas. O mesmo autor afirma, também, que a Salmonella mantém-se viável em queijo contaminado por longo período de tempo.

A identificação de microrganismos do gênero Staphylococcus a partir do leite e derivados é relevante, devido à sua prevalência nos casos de mastite bovina. Paralelamente, esse microrganismo pode ser isolado de diferentes nichos - pele e mucosa do homem, animais e ambiente -e, em determinadas condições, pode causar patogenia humana (FAGUNDES \& OLIVEIRA, 2004; NORMANNO et al., 2005).

A presença desse microrganismo nos produtos lácteos, sob condições apropriadas, pode determinar a produção de enterotoxinas termoestáveis e causar surtos de intoxicação alimentar. A intoxicação ocorre após consumo de alimentos contaminados submetidos a tratamento térmico inadequado ou mantidos sob condições favoráveis à multiplicação da bactéria e produção da toxina (ALMEIDA \& FRANCO, 2003).

Escherichia coli é o principal representante do grupo dos coliformes termotolerantes, por ser um habitante natural do trato entérico do homem e dos animais. Sua presença nos alimentos, incluindo o leite e derivados, indica contaminação fecal direta ou indireta e tem estreita relação com a presença de salmonelas e microrganismos patogênicos de origem entérica (ICMSF, 2000). Tem sido isolado com frequência a partir do leite bovino e já foram identificados alguns sorotipos patogênicos, como a Escherichia coli O157:H7, causadora da enterocolite e da síndrome urêmica hemolítica humana (GARCIA et al., 2008).

Além dos coliformes totais e dos termotolerantes, a quantificação da população de bactérias aeróbias mesófilas e psicrotróficas e de bolores e leveduras representa uma ferramenta útil para indicar as condições de qualidade higiênico-sanitária da produção e comercialização da ricota (FRANCO e LANDGRAF, 2003).

Com esta pesquisa, objetivou-se avaliar as características microbiológicas de ricota comercial produzida sob controle higiênico-sanitário permanente. As análises basearam-se nos padrões da legislação sanitária nacional vigente, a fim de observar se o produto comercializado pode representar risco à saúde do consumidor.

\section{MATERIAL E MÉTODOS}

Foram analisadas sessenta amostras de ricota de fabricação industrial, de duas marcas comerciais, produzidas sob controle higiênico-sanitário permanente, adquiridas em supermercados do estado de São Paulo pelo período de doze meses. As amostras foram processadas no Laboratório de Análise de Alimentos de Origem Animal e Água do Departamento de Medicina Veterinária Preventiva e Reprodução Animal da Facul- 
dade de Ciências Agrárias e Veterinárias, Câmpus de Jaboticabal da Universidade Estadual Paulista.

Avaliaram-se as amostras quanto à presença dos gêneros Listeria e Salmonella, enumeração das populações de Staphylococcus coagulase positivo e $S$. aureus, determinação do número mais provável (NMP) de coliformes totais, termotolerantes e Escherichia coli. Adicionalmente, foi investigada a presença de microrganismos aeróbios ou facultativos mesófilos e psicrotróficos viáveis, bolores e leveduras. Para a realização das análises foi utilizada a metodologia recomendada pelo Compendium of methods for microbiological examination of foods (APHA, 2001), com exceção da pesquisa do gênero Listeria, que seguiu a metodologia preconizada pelo Health Protection Branch of Canada, adotada por SILVA et al. (1998).

Para contagem do gênero Staphylococcus foi utilizada a técnica de semeadura em superfície em ágar Baird-Parker. Decorrido o período de incubação, as colônias características foram contadas e cinco delas foram semeadas em tubos com ágar nutriente inclinado. Após a incubação, prepararam-se esfregaços corados pelo método de Gram e as culturas características foram submetidas à prova de catalase para confirmação do gênero.

O resultado final da contagem de Staphylococcus coagulase positivo foi obtido com base no resultado da prova de coagulase livre, proporcionalmente à população de Staphylococcus. Dentre as cepas coagulase positivas, foi confirmada a presença do Staphylococcus aureus, através das provas da fermentação do manitol em anaerobiose e da produção de acetoína (VP), seguindo a metodologia descrita por Mac FADDIN (1976).

Para pesquisa de gênero Salmonella, 25 gramas de cada amostra foram adicionados a $225 \mathrm{~mL}$ de água peptonada a $0,1 \%$ tamponada. Após a incubação, realizou-se o enriquecimento seletivo em caldo selenito-cistina e em caldo Rappaport-Vassiliadis, acrescidos de novobiocina em uma concentração de quarenta microgramas do princípio ativo por mililitro do meio. Após a incubação, as culturas dos caldos de enriquecimento foram semeadas em ágar verde brilhante e ágar MacConkey.

Das culturas obtidas no plaqueamento seletivo, de três a cinco colônias com características sugestivas do gênero Salmonella foram inoculadas em tubos contendo meio tríplice açúcar ferro (TSI), para identificação presuntiva do gênero.
A técnica para pesquisa de bactérias do gênero Listeria consistiu em um enriquecimento primário em que 25 gramas da amostra foram acrescentados a 225 $\mathrm{mL}$ de caldo de enriquecimento para Listeria (LEB), suplementado com cicloheximida (50 mg/litro), acriflavina ( $15 \mathrm{mg} /$ litro) e ácido nalidíxico (40 mg/litro). Decorrido o período de incubação, $0,1 \mathrm{~mL}$ do caldo foi transferido para tubos com $10 \mathrm{~mL}$ de Caldo Fraser, suplementado com acriflavina ( $25 \mathrm{mg} /$ litro) e ácido nalidíxico (20 mg/litro), constituindo-se em um enriquecimento secundário. Simultaneamente, a cultura em caldo de enriquecimento primário foi semeada, pela técnica de esgotamento, em ágar Oxford modificado (MOX), suplementado de acordo com as instruções do fabricante. ${ }^{1}$ As culturas também foram semeadas em ágar cloreto de lítio feniletanol moxalactam (LPM), suplementado com esculina ( $1,0 \mathrm{~g} /$ litro) e citrato férrico amoniacal (0,5 g/litro), para melhor visualização das colônias. Decorrido o período de incubação do caldo Fraser, este também foi semeado nos meios seletivos MOX e LPM. Colônias negras, regulares com formação de halo escuro, foram consideradas sugestivas do gênero Listeria.

De três a cinco colônias com características sugestivas nos meios seletivos foram submetidas à coloração pelo método de Gram e, posteriormente semeadas em tubos de ágar tripticase de soja, suplementado com $0,6 \%$ de extrato de levedura (TSA-YE). A identificação bioquímica incluiu os testes de catalase, motilidade, nitrato, reação em ágar tríplice açúcar ferro (TSI), verificação de hemólise (CAMP teste) e teste de fermentação de açúcares (dextrose, xilose, rhamnose, manitol, maltose e esculina), segundo metodologia descrita por Mac FADDIN (1976).

\section{RESULTADOS E DISCUSSÃO}

Das sessenta amostras de ricota analisadas, $18,3 \%$ (13,3\% da marca A e 23,3\% da marca B) foram consideradas impróprias para consumo humano por apresentarem contagens de Staphylococcus coagulase positivo superiores a 5,0 x $10^{2} \mathrm{UFC} / \mathrm{g}$. As populações do microrganismo estão divididas em classes e demonstradas na Tabela 1 , onde é possível observar que o maior número de amostras se encontra na faixa de $10^{4}$ a $10^{5} \mathrm{UFC} / \mathrm{g}$.

1 DIFCO-Modified Oxford Antimicrobic Supplement. 
TABELA 1. Distribuição do número e percentual de amostras de ricota das marcas A e B quanto à população de Staphylococcus coagulase positivo em $\mathrm{UFC} / \mathrm{g}$

\begin{tabular}{lcccc}
\hline & UFC/g de Staphylococcus & Marca A & Marca B & Total \\
\hline & coagulase positivo & $\mathrm{N}^{\mathrm{o}}(\%)$ & $\mathrm{N}^{\mathrm{o}}(\%)$ & $\mathrm{N}^{\mathrm{o}}(\%)$ \\
\hline$\leq 5,0 \times 10^{2}$ & & $0(0,0)$ & $0(0,0)$ & $0(0,0)$ \\
$5,0 \times 10^{2} \dashv 5,0 \times 10^{3}$ & & $0(0,0)$ & $1(9,1)^{*}$ & $1(9,1)^{*}$ \\
$5,0 \times 10^{3}-5,0 \times 10^{4}$ & $1(9,1)^{*}$ & $2(18,2)^{*}$ & $3(27,3)^{*}$ \\
$5,0 \times 10^{4}-5,0 \times 10^{5}$ & $2(18,2)^{*}$ & $3(27,3)^{*}$ & $5(45,5)^{*}$ \\
$5,0 \times 10^{5}-5,0 \times 10^{6}$ & $1(9,1)^{*}$ & $0(0,0)$ & $1(9,1)^{*}$ \\
$>5,0 \times 10^{6}$ & $0(0,0)$ & $1(9,1)^{*}$ & $1(9,1)^{*}$ \\
Total & $4(36,4)$ & $7(63,6)$ & $11(100,00)$ \\
\hline
\end{tabular}

* Amostras impróprias para consumo humano, segundo a RDC nº 12-Anvisa (BRASIL, 2001).

Observou-se que todas as amostras de Staphylococcus coagulase positivo foram posteriormente confirmadas como Staphylococcus aureus, mantendo-se a mesma distribuição de contagem do microrganismo. As médias aritméticas encontradas para esse agente foram $3,1 \times 10^{5} \mathrm{UFC} / \mathrm{g}$ e $9,8 \times 10^{5} \mathrm{UFC} / \mathrm{g}$, respectivamente, para as marcas A e B.

Os resultados do presente estudo mostraram que $100 \%$ das amostras avaliadas estavam contaminadas com Staphylococcus coagulase positivo, em desacordo, portanto, com os padrões exigidos pela legislação vigente e, dessa forma, impróprias para consumo humano. A legislação determina, através da Resolução no 12/2001 (BRASIL, 2001), o limite tolerável de 5,0 x 10² UFC/g de Sthapylococcus coagulase positivo em queijos de alta umidade, elaborados por coagulação enzimática, sem a ação de bactérias lácticas. VASCONCELOS et al. (2005) também encontraram altas contagens de Staphylococcus coagulase positivo em ricota de produção industrial: $60 \%$ das amostras analisadas pelos autores foram consideradas impróprias para consumo humano.

Evidencia-se que não houve diferença significativa $(p>0,05)$ entre o número de amostras fora dos padrões legais em ambas as marcas, demonstrando a qualidade insatisfatória do produto, independente da marca analisada.

Em relação ao Staphylococcus aureus, o percentual de $18,3 \%$ de amostras com contagem superior a 5,0 $\mathrm{x} 10^{2} \mathrm{UFC} / \mathrm{g}$ revela o risco que o consumo desse alimento representa para a população, especialmente pela possibilidade de produção de toxinas responsáveis por causar gastrenterite. Segundo NADER FILHO et al. (2007), de $30 \%$ a $50 \%$ dos isolados têm capacidade de produzir uma ou mais enterotoxinas termoestáveis. Um trabalho realizado por NORMANNO et al. (2005) revelou que $83,3 \%$ dos isolados de Staphylococcus aureus provenientes de amostras de ricota eram enterotoxigênicos, evidenciando o risco ao consumidor. Entre os alimentos causadores de surtos e casos de intoxicação estafilocócica destacam-se o leite cru, o leite pasteurizado e os queijos sendo $S$. aureus o microrganismo mais frequente nas investigações epidemiológicas (BORGES, 2008).

No presente estudo, Listeria spp. e Salmonella spp. não foram isoladas a partir das amostras de ricota analisadas. Nesse aspecto, as amostras foram consideradas em conformidade com a Resolução $n^{\circ}$ 12/2001 da Anvisa (BRASIL, 2001), que determina ausência desses microrganismos em 25 gramas do produto analisado. É importante ressaltar, porém, que a ausência desses gêneros nas amostras analisadas pode estar relacionada às características de competição dos agentes, sendo que a presença de outros microrganismos poderia atuar inibindo a multiplicação. A ocorrência desses microrganismos em alimentos está, muitas vezes, associada às contagens menores de outros contaminantes (BRANT et al., 2007).

Os dados da Tabela 2 apontam a distribuição das amostras de ricota, quanto ao NMP por grama de coliformes totais, coliformes termotolerantes e Escherichia coli para as marcas $\mathrm{A}$ e $\mathrm{B}$, sendo que não houve diferença estatística significativa entre ambas quando aplicado o teste de Qui-quadrado $(\mathrm{p}>0,05)$. 
TABELA 2. Distribuição do número e percentual de amostras de ricota das marcas A e B, quanto ao NMP/g de coliformes totais, coliformes termotolerantes e Escherichia coli

\begin{tabular}{|c|c|c|c|c|c|c|}
\hline \multirow{3}{*}{$\mathrm{NMP} / \mathrm{g}$} & \multicolumn{2}{|c|}{ Coliformes totais } & \multicolumn{2}{|c|}{ Coliformes termotolerantes } & \multicolumn{2}{|c|}{ Escherichia coli } \\
\hline & Marca A & Marca B & Marca A & Marca B & Marca A & Marca B \\
\hline & $\mathrm{N}^{\mathrm{o}}(\%)$ & $\mathrm{N}^{\mathrm{o}}(\%)$ & $\mathrm{N}^{\mathrm{o}}(\%)$ & $\mathrm{N}^{\mathrm{o}}(\%)$ & $\mathrm{N}^{\mathrm{o}}(\%)$ & $\mathrm{N}^{\mathrm{o}}(\%)$ \\
\hline$\leq 3,0 \times 10^{0}$ & $0(0,0)$ & $0(0,0)$ & $4(6,7)$ & $5(8,3)$ & $4(6,7)$ & $6(10,0)$ \\
\hline $3,0 \times 10^{0} \dashv 5,0 \times 10^{2}$ & $6(10,0)$ & $5(8,3)$ & $4(6,7)$ & $6(10,0)$ & $4(6,7)$ & $5(8,3)$ \\
\hline $5,0 \times 10^{2} \dashv 5,0 \times 10^{3}$ & $0(0,0)$ & $1(1,7)$ & $1(1,7)^{*}$ & $1(1,7)^{*}$ & $1(1,7)$ & $1(1,7)$ \\
\hline $5,0 \times 10^{3} \dashv 5,0 \times 10^{4}$ & $4(6,7)$ & $1(1,7)$ & $5(8,3)^{*}$ & $1(1,7)^{*}$ & $5(8,3)$ & $2(3,3)$ \\
\hline $5,0 \times 10^{4} \dashv 1,1 \times 10^{5}$ & $1(1,7)$ & $1(1,7)$ & $3(5,0)^{*}$ & $2(3,3)^{*}$ & $3(5,0)$ & $1(1,7)$ \\
\hline $1,1 \times 10^{5} \dashv 1,1 \times 10^{6}$ & $11(18,3)$ & $8(13,3)$ & $8(13,3)^{*}$ & $3(5,0)^{*}$ & $9(15,0)$ & $4(6,7)$ \\
\hline $1,1 \times 10^{6} \dashv 1,1 \times 10^{7}$ & $4(6,7)$ & $4(6,7)$ & $4(6,7)^{*}$ & $3(5,0)^{*}$ & $4(6,7)$ & $6(10,0)$ \\
\hline$>1,1 \times 10^{7}$ & $4(6,7)$ & $10(16,7)$ & $1(1,7)^{*}$ & $9(15,0)^{*}$ & $0(0,0)$ & $5(8,3)$ \\
\hline Total & $30(50,0)$ & $30(50,0)$ & $30(50,0)$ & $30(50,0)$ & $30(50,0)$ & $30(50,0)$ \\
\hline
\end{tabular}

* Amostras impróprias para consumo humano segundo a Resolução no 12/2001 da Anvisa (BRASIL, 2001).

Do total de amostras analisadas, 100\% apresentaram coliformes totais. A legislação brasileira não estabelece limites de tolerância para esse grupo em ricota; entretanto, a contagem indica as condições higiênicas em que o produto foi produzido, uma vez que tais microrganismos, comumente presentes no leite cru, devem ser destruídos pela pasteurização, não estando presentes no leite submetido a tratamento térmico correto. Pode-se, portanto, associar as elevadas populações observadas no presente estudo, tanto para a marca $\mathrm{A}$ quanto para a $\mathrm{B}$, com a recontaminação do produto ocorrida durante as diferentes etapas de produção.

Com base na população de coliformes termotolerantes, observa-se que a maioria das amostras das marcas analisadas estava em desacordo com o padrão microbiológico estabelecido pela Resolução n 12/2001 da Anvisa, a qual determina tolerável para esse tipo de alimento o valor de $5,0 \times 10^{2}$ como sendo o NMP/g de coliformes a $45{ }^{\circ} \mathrm{C}$, (BRASIL, 2001). Populações superiores às estabelecidas pela legislação foram observadas em $22(73 \%)$ amostras da marca A e em dezenove (63\%) da marca B. Assim, das sessenta amostras analisadas, 41 (68\%) estavam impróprias para consumo humano.

Os níveis de coliformes termotolerantes obtidos nesta pesquisa para as marcas A e B são alarmantes, pois sua presença no produto revela contato com conteúdo fecal, seja através da matéria-prima, ou de equipamentos mal higienizados, ou de manipulação higiênica inadequada. Esse quadro é um indicativo de produção sob condições sanitárias insatisfatórias e de presença de microrganismos patogênicos capazes de causar Doenças de Transmissão Alimentar. VASCONCELOS et al., (2005), ao fazer a mesma análise no Rio Grande do Sul encontraram no comércio $25 \%$ de amostras de ricota impróprias para consumo humano.

Entre os diversos microrganismos da microbiota intestinal de animais homeotérmicos, a Escherichia coli é a espécie predominante. No presente estudo, cinquenta (83\%) amostras estavam contaminadas com Escherichia coli, sendo $26(86 \%)$ da marca A e 24 (80\%) da marca B (Tabela 2).

A contagem de bactérias aeróbias mesófilas, psicrotróficas e de bolores e leveduras foi um indicador empregado para verificar a qualidade higiênico-sanitária da produção da ricota. Para o grupo dos psicrotróficos e dos mesófilos, os níveis alcançaram entre $1,0 \times 10^{16}$ e $1,0 \times 10^{18} \mathrm{UFC} / \mathrm{g}$. Com relação aos bolores e leveduras, para a marca A a maioria das amostras situou-se na faixa entre $1,0 \times 10^{5}$ e $1,0 \times$ $10^{6} \mathrm{UFC} / \mathrm{g}$; para a marca $\mathrm{B}$, os valores mais frequentemente encontrados oscilaram entre $1,0 \times 10^{4} \mathrm{e} 1,0$ x $10^{5} \mathrm{UFC} / \mathrm{g}$.

Embora em nossa legislação não existam parâmetros regulamentadores para a presença ou a 
ausência desses microrganismos, o isolamento deles, em níveis elevados nos alimentos pode indicar a existência de condições favoráveis para multiplicação de microrganismos patogênicos. Alguns apresentam potencial deteriorador, causando modificações sensoriais nos produtos diminuindo seu prazo de vida comercial, o que gera impactos negativos para a economia e para a saúde pública, caso os alimentos sejam consumidos inadvertidamente (CARMINATI et al., 2002).

É importante salientar que a ricota é um derivado lácteo consumido em larga escala no Brasil. Geralmente o consumidor adquire esse tipo de produto, de alta digestibilidade, sem gordura ou sal, a fim de auxiliar no controle de distúrbios orgânicos, como parte de uma dieta mais saudável ou para controlar o peso (PINTO et al., 2000). Por essas características, os derivados do leite, especialmente a ricota, são normalmente recomendados para pessoas convalescentes, idosos e crianças. Porém, a ricota é considerada um dos produtos que apresentam as melhores condições para a multiplicação de microrganismos, sejam patogênicos ou deteriorantes. Isso se deve, principalmente, à alta umidade e à disponibilidade de nutrientes, como sais minerais e lactose, o que compromete a qualidade do produto e sua vida de prateleira (MAIA et al., 2004). No caso da ricota tem-se a associação entre dois fatores importantes do ponto de vista da saúde pública: população consumidora, formada muitas vezes por indivíduos com o sistema imunológico comprometido; e alimento que alberga todas as características necessárias para a veiculação de diferentes agentes patogênicos.

\section{CONCLUSÃO}

A maior parte das amostras de ricota analisadas neste experimento encontrava-se em desacordo com os padrões exigidos legalmente. A ricota, mesmo produzida sob controle higiênico-sanitário permanente, pode representar risco à saúde do consumidor, especialmente pelas altas contagens de Staphylococcus aureus, coliformes termotolerantes e Escherichia coli. Além disso, a presença de microrganismos psicrotróficos, mesófilos, bolores e leveduras em níveis elevados revela que as condições higiênicas de obtenção do produto são insatisfatórias.

\section{REFERÊNCIAS}

ALMEIDA, P. M. P.; FRANCO, R. M. Avaliação bacteriológica de queijo tipo minas frescal com pesquisa de patógenos importantes à saúde pública: Staphylococcus aureus, Salmonella spp., e coliformes fecais. Revista Higiene Alimentar, v. 17, n. 111, p. 79-85, 2003.

APHA. American Public Health Association. Committe on microbiologycal methos for foods. Compendiun of Methods for the Microbiologycal Examination of Foods. Washington, Apha, $2001.676 \mathrm{p}$.

BORGES, M. F. Staphylococcus enterotoxigênicos em leite e produtos lácteos, suas enterotoxinas e genes associados: revisão. Boletim do Centro de Pesquisa e Processamento de Alimentos: UFPR, v. 26, n. 1, p. 71-86, 2008.

BRANT, L. M. F.; FONSECA, L. M.; SILVA, M. C. C. Avaliação da qualidade microbiológica de queijo-de-minas artesanal do SerroMG. Arquivo Brasileiro de Medicina Veterinária e Zootécnica, v. 59, n. 6, p. 1.570-1.574, 2007.

BRASIL. Ministério da Saúde. Resolução nº. 12, de 2 de janeiro de 2001. Regulamento Técnico Sobre os Padrões Microbiológicos para Alimentos. Art. 4ª Diário Oficial [da] União, Brasília, 2001. 1-48 p.

CARMINATI, D.; BELLINI, E.; PERRONE, A.; NEVIANI, E.; MUCCHETTI, G. Traditional Ricotta cheese survery of the microbiological quality and its shelf-life. Industrie Alimentari, v. 41, n. 414, p. 549-555, 2002.

FAGUNDES, H.; OLIVEIRA, C. A. F. Infecções intramamárias causadas por Staphylococcus aureus e suas implicações em saúde pública. Ciência Rural, v. 34, n. 4, p. 1.315-1.320, 2004.

FEITOSA, T.; BORGES M. F.; NASSU, R. T.; AZEVEDO, E. H. F.; MUNIZ, C. M. Pesquisa de Salmonella sp., Listeria sp. e microrganismos indicadores higiênico-sanitários em queijos produzidos no estado do Rio Ggrande do Norte. Ciência e Tecnologia de Alimentos, v. 23, n. 3, p. 162-165, 2003.

FRANCO, B. D. G. M.; LANDGRAF, M. Microbiologia dos alimentos. São Paulo: Atheneu, 2003. 182 p.

GARCIA, P. M.; ARCURI, E. F.; BRITO, M. A. V. P.; LANGE, C. C.; BRITO, J. R. F.; CERQUEIRA, M. M. O. P. Deteç̧ão de Escherichia coli O157:H7 inoculada experimentalmente em amostras de leite cru por método convencional e PCR multiplex. Arquivo Brasileiro de Medicina Veterinária e Zootécnica, v. 60, n. 5 , p. 1.241-1.249, 2008 .

GUERRA, M. M.; BERNARDO, F. M. Ocorrência natural de Listeria spp. em queijos alentejanos. Revista Portuguesa de Ciências Veterinárias, v. 94, n. 531, p. 142-148, 1999. 
ICMSF. International Committee on Microbiological Specification for Food. Microrganismos de los alimentos: su significado y metodos de enumeracion. Zaragoza: Acribia, 2000. 439 p.

MAIA, S. R.; FERREIRA, A. C.; ABREU, L. R. Uso do açafrão (Curcuma longal) na redução da Escherichia coli e Enterobacter aerogenes em ricota. Ciência e Agrotecnologia, v. 28, n. 2, p. 358-365, 2004.

NADER FILHO, A.; FERREIRA, L. M.; AMARAL, L. A.; ROSSI JR., O. D.; OLIVEIRA, R. P. Produção de enterotoxinas e da toxina da síndrome do choque tóxico por cepas de Staphylococcus aureus isoladas na mastite bovina. Arquivo Brasileiro de Medicina Veterinária e Zootécnica, v. 59, n. 5, p. 1.316-1.318, 2007.

NORMANNO, G.; FIRINU, A.; VIRGILIO, S.; MULA, G.; DAMBROSIO, A.; POGGIU, A.; DECASTELLI, L.; MIONI, R.; SCUOTA, S.; BOLZONI, G.; DI GIANNATALE, E.; SALINETTI, A. P. Coagulase-positive Staphylococci and Staphylococcus aureus in food products marketed in Italy. International Journal of Food Microbiology, v. 98, p. 73-79, 2005.

PINTADO, M. E.; MACEDO, A. C.; MALCATA, F. X. Technology, chemisty and microbiology of whey cheeses. Food Science and Technology International, v. 7, n. 2, p. 105-116, 2001.
PINTO, S. M.; ABREU, L. R.; SILVEIRA, I. A.; CARVALHO, E. P.; MOURA, C. J. Avaliação das características físico-químicas de queijo ricota comercializados em Lavras-MG. Revista do Instituto de Laticínios Cândido Tostes, v. 54, n. 313, p. 20-22, 2000.

RIBEIRO, A. C.; MARQUES, S. C.; SODRÉ, A. F.; ABREU, L. R.; PICCOLI, R. H. Controle microbiológico da vida de prateleira de ricota cremosa. Ciência e Agrotecnologia, v. 29, n. 1, p. 113-117, 2005.

SILVA, M. C. D.; HOFER, E.; TIBANA, A. Incidence of Listeria monocytogenes in cheese produced in Rio de Janeiro, Brazil. Journal of Food Protection, v. 61, n. 3, p. 354-356, 1998.

SOUZA, R. M. B.; SOFFIATTI, I. H. B.; MARTELLI, M. C.; PENA, R. S. Avaliação de características físico-químicas de queijo cottage $\mathrm{e}$ ricota comercializados em Belo Horizonte (MG). Revista do Instituto de Laticínios Cândido Tostes, v. 57, n. 327, p. 291-294, 2002.

VASCONCELOS, F.; ROCHA, A.; RIBEIRO, G. Detecção de Staphylococcus coagulase positiva e coliformes termotolerantes em queijo ricota comercializado na cidade de Pelotas-RS. In: CONGRESSO DE INICIAÇÃO CIENTÍFICA DA UFPel, 2005, Pelotas. Anais eletrônicos ... Pelotas: UFPel, 2005. Disponível em: <http://www.ufpel.edu.br/cic/2005/arquivos/CB_00455.rtf>. Acesso em: 29jul. 2010.

Protocolado em: 2 jun. 2009. Aceito em: 30 set. 2010. 